\title{
Treatment of post-prostatectomy urinary incontinence and erectile dysfunction: there is insufficient utilisation of care in German cancer survivors
}

\author{
Martin Baunacke ${ }^{1} \cdot$ Maria-Luisa Schmidt ${ }^{1} \cdot$ Christer Groeben $^{1} \cdot$ Angelika Borkowetz $^{1} \cdot$ Christian Thomas $^{1}$. \\ Rainer Koch ${ }^{1}$ - Falk Hoffmann ${ }^{2}$ - Felix K. H. Chun ${ }^{3}$ - Lothar Weissbach ${ }^{4}$. Johannes Huber ${ }^{1}$ (])
}

Received: 14 August 2020 / Accepted: 9 November 2020 / Published online: 1 December 2020

(c) The Author(s) 2020

\begin{abstract}
Purpose Treatment of post-prostatectomy urinary incontinence (UI) and erectile dysfunction (ED) increases quality of life (QoL). Aim of our study was to evaluate the utilisation of care among patients with post-prostatectomy UI and ED in Germany.

Methods The HAROW study documented treatment of patients with localised prostate cancer $(\leq \mathrm{T} 2 \mathrm{c})$ in Germany. 1260 patients underwent radical prostatectomy (RP). Patients answered validated questionnaires after a median follow-up of 6.3 years. Response rate was $76.8 \%$.

Results Median age at RP was 65 (IQR 60-69) years. 14\% (134/936) used more than one pad per day for UI. 25\% (26/104, 30 missing) of UI patients underwent surgery to improve continence. Of patients without surgery, $41 \%$ (31/75) reported a moderate-to-severe issue concerning their incontinence with worse mental health and QoL. 81\% (755/936) patients were unable to have an erection firm enough for sexual intercourse. Of all ED patients, 40\% (319/793) used ED treatment regularly or tried it at least once. 49\% (243/499) of patients with interest in sex never tried ED treatment. In multivariate analysis, patients not using ED treatments were older ( $\geq 70$ years OR 4.1), and more often had preoperative ED (OR 2.3) and less interest in sex (OR 2.2). Nevertheless, 30\% (73/240) of these patients had moderate-to-severe issues with their ED reporting worse mental health and QoL.

Conclusion Almost half of the patients without post-prostatectomy UI and ED treatment reported moderate-to-severe issues with a significant decrease in QoL. This indicates an insufficient utilisation of care in Germany.
\end{abstract}

Keywords Prostatectomy $\cdot$ Erectile dysfunction $\cdot$ Incontinence $\cdot$ Health services research

Electronic supplementary material The online version of this article (https://doi.org/10.1007/s00345-020-03526-z) contains supplementary material, which is available to authorized users.

Johannes Huber

johannes.huber@uniklinikum-dresden.de

1 Department of Urology, TU Dresden, Fetscherstrasse 74, 01307 Dresden, Germany

2 Department of Health Services Research, Carl Von Ossietzky University, Ammerlaender Heerstrasse 140, 26111 Oldenburg, Germany

3 Department of Urology, Goethe-University Hospital, Theodor-Stern-Kai 7, 60590 Frankfurt, Germany

4 Health Research for Men gGmbH, Gfm, Claire-Waldoff-Strasse 3, 10117 Berlin, Germany

\section{Introduction}

Urinary incontinence (UI) and erectile dysfunction (ED) are the two most relevant side effects after radical prostatectomy (RP). Reported UI rates after RP vary between four and $40 \%$ [1], and ED rates vary between 10 and 69\% [2]. Both functional outcomes are of critical importance for future quality of life [3].

In the majority of patients, UI can be treated by conservative and surgical treatment. For patients with persistent incontinence after one year of conservative treatment, including treatment with drugs, a surgical intervention can be used to improve their urinary continence [4]. There is a wide range of surgically implantable devices, including adjustable and non-adjustable male slings as well as artificial sphincters [5]. The artificial sphincter, being the most 
invasive surgical procedure, is the gold standard for the treatment of UI after RP [6].

Oral phosphodiesterase type 5 (PDE5) inhibitors represent the standard pharmacologic treatment for ED. Escalating ED treatment comprises intraurethral medication, penile injection therapy, vacuum erection devices, and penile prostheses [7]. Penile prostheses are the only surgical treatment option and show high patient satisfaction in a selected population [8].

Because poor functional outcomes after RP are burdensome, it is important to offer patients adequate and effective treatment. However, despite the great variety of therapy options for UI and ED, to date, little is known about the utilisation of available treatments in most healthcare systems. The aim of our study was to evaluate the utilisation of available treatments for post-prostatectomy incontinence and ED in a large cohort of patients receiving routine care in Germany.

\section{Materials and methods}

The HAROW study (Hormone Therapy, Active Surveillance, Radiation, Operation, or Watchful Waiting) was a prospective observational noninterventional health services research study in Germany from 2008-2013 that evaluated the treatment of patients with histologically confirmed localised prostate cancer (T1a-T2c/N0/M0) [9]. Of this cohort, 1260 patients underwent radical prostatectomy. To evaluate the utilisation of treatment for post-prostatectomy UI and $\mathrm{ED}$, we sent questionnaires to the participants by mail in Feb 2017. Non-responders were contacted by phone.

To evaluate the utilisation of available treatments for post-prostatectomy incontinence and ED, we analysed total utilisation of these treatments. We further analysed patients not using treatments regarding their level of burden because of their impairment and influence on quality of life. For ED, we analysed the subgroup of patients who were still interested in sex.

For these evaluations, we asked about use of ED treatment and interventions to improve continence. For ED treatment, we asked for use of PDE5 inhibitors, intraurethral medications, penile injection therapy, vacuum erection devices and penile prosthesis. Interventions to improve continence included slings, systems (ATOMS or ProAct), artificial sphincters, and other surgical procedures. Moreover, we evaluated d'Amico risk classification and Charlson score. Different validated questionnaires were used to measure functional outcome: The EPIC-26 questionnaire identified the extent of incontinence and urinary symptoms [10]. We defined UI by the use of two or more pads per day or having undergone incontinence surgery. Sexual function was validated according to ICHOM standards [11] with two additional questions from the EORTC QLQ-PR25 questionnaire [12] and one validated item on the use of erectile dysfunction aids [13]. Potency was defined by an erection firm enough for sexual intercourse without reporting ED treatment. Interest in sex was defined by small to large interest in sex according the EORTC QLQ-PR25 questionnaire [12]. Four items from the EORTC-QOL-30 questionnaire [14] were used to evaluate the overall quality of life and social sequelae. We used the PHQ-4 to evaluate mental health [15]. Furthermore, we assessed the patient's Internet use concerning health issues. We applied the Chi-square test, the Mann-Whitney $U$ test, and multivariate logistic analyses. $p<0.05$ was considered to indicate significance. All calculations were performed with "IBM SPSS Statistics 22" (Armonk, NY, USA) and SAS V9.4 (SAS Institute, Cary, NC, USA).

\section{Results}

The median age at surgery was 65 (IQR, 60-69) years. After a median follow-up of 6.3 [interquartile range (IQR) 4.8-7.6] years, 3\% (42) had died. The response rate was 76.8\% (936/1218). Responders and non-responders showed no relevant differences in age, oncological risk, Charlson score, or surgical approach. The whole collective was recently published [16]. Therein 404 patients underwent robotic-assisted radical prostatectomy (RARP) und 532 patients open retropubic prostatectomy (ORP). Urinary continence rate was $83 \%$ after RARP and $89 \%$ after RARP. Potency rate of preoperatively potent patients with nervesparing surgery was $47 \%$ after RARP and $36 \%$ after ORP. In multivariate analysis, there was no difference in functional outcome between both approaches.

\section{Urinary incontinence}

After a median follow-up of 6.3 years after RP, $14 \%$ (134/936) of patients were incontinent, and 25\% (26/104, 30 missing) of these patients underwent incontinence surgery. Forty-six percent $(12 / 26)$ of these patients received slings, $12 \%$ (3/26) received systems (ATOMS or ProAct), $38 \%(10 / 26)$ received artificial sphincters and 15\% (4/26) received other surgical procedures. Three of 26 (12\%) patients underwent multiple surgeries. Comparing incontinent patients who did and did not undergo incontinence surgery, there was no difference in age $(65.8 \pm 8.8$ vs. $66.7 \pm 6.1, p=0.6)$, Charlson score $(2+81 \%$ vs. $86 \%$, $p=0.2$ ) or d'Amico score (high risk 42 vs. $43 \%, p=0.9$ ). Patients who underwent surgery used fewer pads ( $\geq 2$ pads 42 vs. $100 \%, p<0.001)$ and showed a better EPIC urinary 
incontinence score $(24.2 \pm 17.6$ vs. $54.4 \pm 37.8, p<0.001)$ (Suppl Table 1).

$41 \%$ (31/75, 3 missing) of UI patients indicated moderate-to-severe disease. Analysing this subpopulation, there was no difference in age $(66.8 \pm 5.8$ vs. $66.7 \pm 6.6$, $p=1.0)$, Charlson score $(2+86 \%$ vs. $86 \%, p=0.7)$ or d'Amico score (high risk 40 vs. $52 \%, p=0.3$ ) compared to the whole cohort. Patients moderately to severely affected by UI showed worse mental health (PHQ-4 Depression score $(1.3 \pm 1.3$ vs. $0.6 \pm 0.9, p=0.02)$, PHQ-4 anxiety score $(1.4 \pm 1.4$ vs. $0.6 \pm 1.0, p=0.007)$, PHQ-4 total score $(2.8 \pm 2.7$ vs. $1.2 \pm 1.5, p=0.005))$ and worse quality of life (EORTC Global Health score $(50.3 \pm 20.0$ vs. $68.2 \pm 19.9, p<0.001)$, EORTC Social Functioning score $(48.9 \pm 25.1$ vs. $85.2 \pm 17.7, p<0.001))$. These patients also had a worse EPIC urinary incontinence score $(13.4 \pm 14.0$ vs. $31.7 \pm 16.4, p<0.001)$ and EPIC urinary irritative symptoms score $(67.0 \pm 14.3$ vs. $84.9 \pm 12.7$, $p<0.001$ ) (Table 1).

\section{Erectile dysfunction}

$81 \%$ (755/936) of patients were impotent after RP, and 7\% (63/936) indicated no impotence after RP but were using ED treatment. Of all evaluable patients with ED, 40\% (319/793) used ED treatment regularly or tried it at least once. Of these patients, 75\% (239/319) used oral PDE5 inhibitors, 10\% (32/319) used intraurethral medications, 17\% (55/319) used penile injection therapy, $38 \%(121 / 319)$ used vacuum erection devices, and no patient underwent surgery for penile prostheses. There was no difference in usage of antiandrogen ( 5 vs. $8 \% ; p=0.08$ ).

A total of $64 \%$ (499/780) of ED patients were still interested in sex, and 49\% (243/499) of them never tried ED treatments. These patients were older $(65.8 \pm 5.1$ vs. $61.8 \pm 6.6$ years, $p<0.001)$, had a higher Charlson score $(2+: 89$ vs $67 \%, p<0.001)$, had fewer problems with impaired sexual function (70 vs. $57 \%, p=0.003$ ) and used the Internet less often for health issues (66 vs. 78\%, $p=0.03$ ) (Suppl. Table 2). In multivariate analysis, patients not using

Table 1 Incontinent patients without surgery by distress regarding their UI $(n=75)$

\begin{tabular}{|c|c|c|c|c|}
\hline Variable & All $(n=75)$ & No to small problem $(n=44)$ & $\begin{array}{l}\text { Moderate to large } \\
\text { problem }(n=31)\end{array}$ & $p$ value \\
\hline $\begin{array}{l}\text { Age (years) [mean } \pm \text { standard deviation, } \\
\text { median (IQR)] }\end{array}$ & $\begin{array}{l}66.7 \pm 6.1 \\
67.0(51.0-77.0)\end{array}$ & $\begin{array}{l}66.8 \pm 5.8 \\
67.0(57.0-77.0)\end{array}$ & $\begin{array}{l}66.7 \pm 6.6 \\
67.0(51.0-76.0)\end{array}$ & 1.0 \\
\hline \multicolumn{5}{|l|}{ Age adjusted Charlson score (2 missing) } \\
\hline 0 & $0(0 \%)$ & $0(0 \%)$ & $0(0 \%)$ & 0.7 \\
\hline 1 & $10(14 \%)$ & $6(14 \%)$ & $4(14 \%)$ & \\
\hline $2+$ & $63(86 \%)$ & $38(86 \%)$ & $25(86 \%)$ & \\
\hline \multicolumn{5}{|l|}{ D’Amico score (1 missing) } \\
\hline Low & $13(17 \%)$ & $10(23 \%)$ & $3(10 \%)$ & 0.3 \\
\hline Intermediate & $28(38 \%)$ & $16(37 \%)$ & $12(39 \%)$ & \\
\hline High & $33(45 \%)$ & $17(40 \%)$ & $16(51 \%)$ & \\
\hline \multicolumn{5}{|l|}{ Internet usage } \\
\hline Daily & $29(39 \%)$ & $18(41 \%)$ & $11(35 \%)$ & 0.8 \\
\hline At least once per week & $13(17 \%)$ & $7(16 \%)$ & $6(19 \%)$ & \\
\hline Rare & $9(12 \%)$ & $4(9 \%)$ & $5(16 \%)$ & \\
\hline No internet & $24(32 \%)$ & $15(34 \%)$ & $9(29 \%)$ & \\
\hline PHQ-4 depression & $\begin{array}{l}0.9 \pm 1.1 \\
0.5(0.0-4.0)\end{array}$ & $\begin{array}{l}0.6 \pm 0.9 \\
0.0(0.0-3.0)\end{array}$ & $\begin{array}{l}1.3 \pm 1.3 \\
1.0(0.0-4.0)\end{array}$ & 0.02 \\
\hline PHQ-4 anxiety & $\begin{array}{l}0.9 \pm 1.2 \\
0.0(0.0-5.0)\end{array}$ & $\begin{array}{l}0.6 \pm 1.0 \\
0.0(0.0-4.0)\end{array}$ & $\begin{array}{l}1.4 \pm 1.4 \\
1.0(0.0-5.0)\end{array}$ & 0.007 \\
\hline PHQ-4 total & $\begin{array}{l}1.8 \pm 2.2 \\
1.0(0.0-9.0)\end{array}$ & $\begin{array}{l}1.2 \pm 1.5 \\
0.0(0.0-5.0)\end{array}$ & $\begin{array}{l}2.8 \pm 2.7 \\
2.0(0.0-9.0)\end{array}$ & 0.005 \\
\hline EORTC global health & $\begin{array}{l}60.8 \pm 21.7 \\
66.7(0.0-100.0)\end{array}$ & $\begin{array}{l}68.2 \pm 19.9 \\
66.7(0.0-100.0)\end{array}$ & $\begin{array}{l}50.3 \pm 20.0 \\
50.0(16.7-83.3)\end{array}$ & $<0.001$ \\
\hline EORTC social functioning & $\begin{array}{l}70.5 \pm 27.5 \\
66.7(0.0-100.0)\end{array}$ & $\begin{array}{l}85.2 \pm 17.7 \\
91.7(33.3-100.0)\end{array}$ & $\begin{array}{l}48.9 \pm 25.1 \\
50.0(0.0-100.0)\end{array}$ & $<0.001$ \\
\hline EPIC urinary continencet & $\begin{array}{l}24.1 \pm 17.8 \\
22.8(0.0-75.0)\end{array}$ & $\begin{array}{l}31.7 \pm 16.4 \\
29.0(6.3-75.0)\end{array}$ & $\begin{array}{l}13.4 \pm 14.0 \\
8.3(0.0-56.3)\end{array}$ & $<0.001$ \\
\hline EPIC urinary irritative symptoms & $\begin{array}{l}77.9 \pm 15.9 \\
81.3(37.5-100.0)\end{array}$ & $\begin{array}{l}84.9 \pm 12.7 \\
87.5(62.5-100.0)\end{array}$ & $\begin{array}{l}67.0 \pm 14.3 \\
68.8(37.5-100.0)\end{array}$ & $<0.001$ \\
\hline
\end{tabular}

Bold values denote statistical significance at the $\mathrm{p}<0.05$ level 
ED treatments were older [60-69 years OR 2.9 (1.8-4.7), $p<0.001 ; 70$ years OR $4.1(2.2-7.7), p<0.001)$, had preoperative ED more often (OR $2.3(1.5-3.4), p<0.001$ ), were less interested in sex (OR $2.2(1.5-3.3), p<0.001)$ and reported fewer problems regarding their ED (OR 1.8 (1.2-2.6), $p=0.006$ ) (Fig. 1).

Nevertheless, 30\% (73/240, 3 missing) of patients with ED not using ED treatments, but with an active interest in sex reported moderate to large problems because of their ED. Patients with moderate to large problems because of their ED showed worse mental health [PHQ-4 depression score $(1.1 \pm 1.3$ vs. $0.4 \pm 0.7, p<0.001)$, PHQ-4 anxiety score $(0.9 \pm 1.2$ vs. $0.4 \pm 0.7, p=0.005)$, PHQ-4 total score $(1.9 \pm 2.4$ vs. $0.8 \pm 1.3, p<0.001)]$ and worse quality of life [EORTC Global Health score $(68.7 \pm 19.9$ vs. $78.5 \pm 16.2$, $p<0.001)$, EORTC social functioning score $(75.3 \pm 26.5$ vs. $91.6 \pm 13.8, p<0.001)]$. These patients also had a worse EPIC sexual function score $(18.2 \pm 18.0$ vs. $36.1 \pm 19.9$, $p<0.001$ ) (Table 2).

\section{Discussion}

This study evaluated the utilisation of care for post-prostatectomy UI and ED in a large cohort of patients undergoing routine care in Germany. 25\% (26/104) of incontinent patients underwent surgery to improve continence. Of the remaining patients without surgery, $41 \%$ (31/75) reported a moderate to large problem concerning their incontinence with worse mental health and quality of life $(p<0.001)$. A total of 49\% (243/499) of ED patients still interested in sex never used ED treatments. 30\% (73/240, 3 missing) of these patients not using ED treatment had moderate to large problems because of their ED. They reported worse mental health and quality of life than patients with no or small problems $(p<0.001)$.

There are few studies examining the use of incontinence surgery after radical prostatectomy. Kim et al. examined this topic in a large US population-based study (SEER registry) with 16,348 men after RP [17]. The data correspond with our results concerning the relative frequency of different incontinence procedures. Kim et al. showed that after RP, only $6 \%$ of patients underwent incontinence surgery. Because of this low percentage, they assumed an underuse of beneficial procedures. In our study, only $2 \%$ (26/936) of all RP patients underwent incontinence surgery. In contrast to Kim et al., we can show very detailed data concerning urinary continence and quality of life. With this profound picture of long-term functional outcomes [16, 18], we can confirm the assumption that there is an underuse of incontinence surgery more securely. However, there are patients with UI using two or more pads per day who are still comfortable with their situation. In our study, 56\% (44/78) of incontinent patients without incontinence surgery reported no or only small distress because of their incontinence. However, 31/78 (44\%) patients reported moderate-to-great distress because of their incontinence. In the Scandinavian Prostate Cancer Group-4 study, 68\% (48/71) of patients with urinary leakage reported moderate-to-great distress because of their incontinence symptoms [19]. Analysing mental health and quality of life in our study shows that $44 \%$ (31/78) of patients without surgery who reported moderate-to-great distress had worse scores for depression, anxiety, global health, and social functioning. Therefore, there is an urgent need for improving urinary continence in these patients. Considering the population-based data from the USA [17], this problem
Fig. 1 Multivariate analysis of patients not using ED treatment

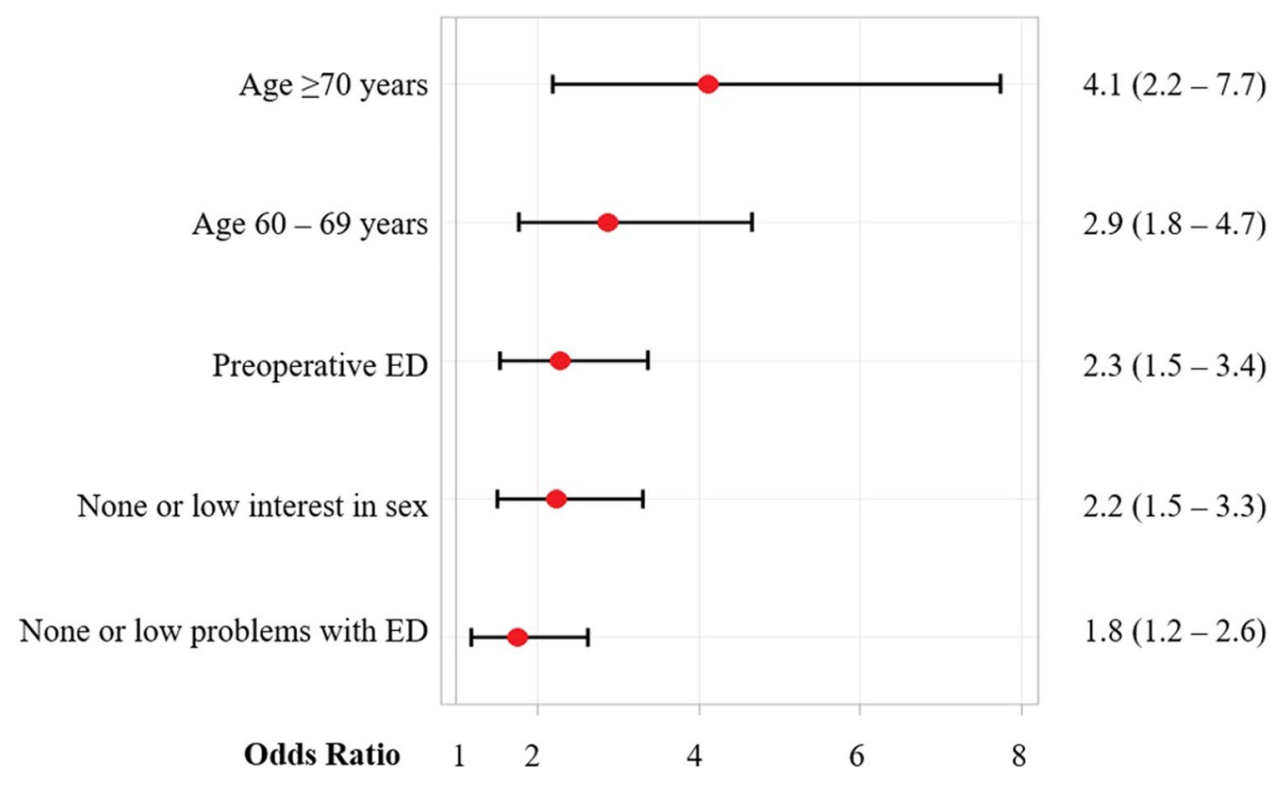


Table 2 Patients with ED, active interest in sex, and without ED treatment by distress regarding their sexual function $(n=240)$

\begin{tabular}{|c|c|c|c|c|}
\hline Variable & All $(n=240)$ & No or small problem $(n=167)$ & $\begin{array}{l}\text { Moderate or big prob- } \\
\text { lem }(n=73)\end{array}$ & $p$ value \\
\hline $\begin{array}{l}\text { Age (years) }[\text { mean } \pm \text { standard deviation, } \\
\text { median (IQR)] }\end{array}$ & $\begin{array}{l}65.8 \pm 5.1 \\
66.0(48.0-77.0)\end{array}$ & $\begin{array}{l}65.9 \pm 5.1 \\
66.0(51.0-77.0)\end{array}$ & $\begin{array}{l}65.7 \pm 5.2 \\
66.0(48.0-76.0)\end{array}$ & 0.7 \\
\hline \multicolumn{5}{|l|}{ Age adjusted Charlson score (5 missings) } \\
\hline 0 & $1(1 \%)$ & $0(0 \%)$ & $1(1 \%)$ & 0.04 \\
\hline 1 & $24(10 \%)$ & $20(12 \%)$ & $4(6 \%)$ & \\
\hline $2+$ & $210(89 \%)$ & $144(88 \%)$ & $66(93 \%)$ & \\
\hline \multicolumn{5}{|l|}{ D'Amico score (1 missing) } \\
\hline Low & $69(28 \%)$ & $51(31 \%)$ & $18(25 \%)$ & 0.6 \\
\hline Intermediate & $85(36 \%)$ & $59(35 \%)$ & $26(36 \%)$ & \\
\hline High & $85(36 \%)$ & $57(34 \%)$ & $28(39 \%)$ & \\
\hline \multicolumn{5}{|l|}{ Preoperative potency } \\
\hline Potent & $74(31 \%)$ & $52(31 \%)$ & $22(30 \%)$ & 0.9 \\
\hline Impotent (or missing) & $166(69 \%)$ & $115(69 \%)$ & $51(70 \%)$ & \\
\hline \multicolumn{5}{|l|}{ Nerve-sparing (10 missing) } \\
\hline Yes & $143(62 \%)$ & $102(64 \%)$ & $41(58 \%)$ & 0.7 \\
\hline No & $55(24 \%)$ & $36(23 \%)$ & $19(27 \%)$ & \\
\hline Unknown & $32(14 \%)$ & $21(13 \%)$ & $11(15 \%)$ & \\
\hline \multicolumn{5}{|l|}{ Internet usage (1 missing) } \\
\hline Daily & $120(50 \%)$ & $87(52 \%)$ & $33(45 \%)$ & 0.5 \\
\hline At least once per week & $38(16 \%)$ & $26(16 \%)$ & $12(16 \%)$ & \\
\hline Rare & $26(11 \%)$ & $19(11 \%)$ & $7(10 \%)$ & \\
\hline No internet & $55(23 \%)$ & $34(21 \%)$ & $21(29 \%)$ & \\
\hline PHQ depression & $\begin{array}{l}0.6 \pm 1.0 \\
0.0(0.0-5.0)\end{array}$ & $\begin{array}{l}0.4 \pm 0.7 \\
0.0(0.0-3.0)\end{array}$ & $\begin{array}{l}1.1 \pm 1.3 \\
0.0(0.0-5.0)\end{array}$ & $<0.001$ \\
\hline PHQ anxiety & $\begin{array}{l}0.5 \pm 0.9 \\
0.0(0.0-5.0)\end{array}$ & $\begin{array}{l}0.4 \pm 0.7 \\
0.0(0.0-3.0)\end{array}$ & $\begin{array}{l}0.9 \pm 1.2 \\
0.0(0.0-5.0)\end{array}$ & 0.005 \\
\hline PHQ total & $\begin{array}{l}1.1 \pm 1.8 \\
0.0(0.0-10.0)\end{array}$ & $\begin{array}{l}0.8 \pm 1.3 \\
0.0(0.0-5.0)\end{array}$ & $\begin{array}{l}1.9 \pm 2.4 \\
1.0(0.0-10.0)\end{array}$ & $<0.001$ \\
\hline EORTC global health & $\begin{array}{l}75.5 \pm 18.0 \\
83.3(16.7-100.0)\end{array}$ & $\begin{array}{l}78.5 \pm 16.2 \\
83.3(16.7-100.0)\end{array}$ & $\begin{array}{l}68.7 \pm 19.9 \\
66.7(16.7-100.0)\end{array}$ & $<0.001$ \\
\hline EORTC social functioning & $\begin{array}{l}86.6 \pm 20.1 \\
100.0(0.0-100.0)\end{array}$ & $\begin{array}{l}91.6 \pm 13.8 \\
100.0(50.0-100.0)\end{array}$ & $\begin{array}{l}75.3 \pm 26.5 \\
83.3(0.0-100.0)\end{array}$ & $<0.001$ \\
\hline EPIC sexual function & $\begin{array}{l}30.6 \pm 21.0 \\
26.3(0.0-94.5)\end{array}$ & $\begin{array}{l}36.1 \pm 19.9 \\
34.7(8.3-94.5)\end{array}$ & $\begin{array}{l}18.2 \pm 18.0 \\
12.5(0.0-61.2)\end{array}$ & $<0.001$ \\
\hline
\end{tabular}

Bold values denote statistical significance at the $\mathrm{p}<0.05$ level

seems to exist beyond the German health care system. In our cohort, there was no difference in age $(p=0.6)$ or age-adjusted Charlson score $(p=0.2)$ between incontinent patients with and without incontinence surgery. Therefore, no medical reasons, such as high age or severe comorbidity, explain the lack of surgical treatment. There are several studies indicating insufficient or problematic communication between physicians and patients, including a relevant discrepancy in patient's perception [20] or significant differences between physician and patient assessments of urinary function [21]. However, these communication issues might be only part of the problem. Inherent health care system factors may also impose restrictions on access and supply of adequate treatment. It is essential to explore these reasons for insufficient utilisation of care to correct them specifically.

Numbers concerning ED treatment use vary widely. A German survey study with 642 patients after RP showed a similar use pattern with regard to the dominance of oral medication $(39 \%)$ and the low number of penile prostheses $(0.3 \%)$ [22]. In our study, we showed a much higher usage of oral medication $(75 \% ; 239 / 319)$, which should be the result of studies of on-demand or regular use of PDE5 inhibitors after nerve-sparing RP [23] and lower prices for oral medication in comparison to 2006, when the mentioned study was published. Surprisingly, there were no patients who underwent penile prosthesis implantation in our nationwide population of 818 patients. An analysis 
of the US SEER-Medicare database has already shown an underutilisation of penile prostheses, with only $2.3 \%$ utilisation after RP [24].

In a retrospective US single-centre study, Miller et al. also discussed a deficiency in ED treatment utilisation [13]. Herein, $31 \%$ of patients suffering from ED after RP never received ED treatment. In our study, we identified some plausible parameters associated with not using ED treatment: older age, less interest in sex and fewer problems with ED. A large multicentre study from six countries identified 4622 patients with ED and showed that older age and less interest in sex were barriers to seeking help [25]. In particular, older men lose their desire for treatment and cope with $\mathrm{ED}$ as a natural part of ageing. This coping strategy might be a good solution for some of these patients but it is important to identify and motivate men who do suffer from ED. In our study, 30\% (73/240) of patients with ED and an active interest in sex reported a significantly worse quality of life and higher scores for depression and anxiety. Therefore, there is an urgent need for treatment in this population. Miller et al. reported that $24 \%$ of US patients who complained about moderate to large problems because of their ED and had not received treatment [13]. With a similar percentage, the insufficient utilisation of care for ED patients appears to be an issue across borders. Analogous to the deficit in incontinence surgery utilisation, there may be communication problems between physicians, patients, and their spouses concerning ED [26]. A German study showed that only 53\% of post-prostatectomy patients were asked about their erectile function during follow-up care [27]. Often, the Internet is the primary source of information for these patients [28]. Another German survey of 642 patients after RP showed that urologists estimated that $45 \%$ of their patients wanted no treatment for ED, while only $29 \%$ of the patients actually did not want any kind of ED treatment [22]. These numbers illustrate a missed opportunity for better care, as patients suffering from ED after RP are closely tied to their urologists during aftercare appointments. Nevertheless, further studies are needed to investigate specific reasons for insufficient access to ED treatment.

In conclusion, similar findings of insufficient utilisation of incontinence and ED treatment were also found in the US. But the financial aspect as a reason for this lack of utilisation may differ because of different health care systems. In the US, there exist greater differences in insurance status and available financing of health care because of a lack of a uniform national health care system. In Germany, the health care system is publicly financed, and every insured person is entitled to the same standard of medical care. Incontinence surgery, vacuum erection devices, and penile prosthesis are covered by health insurance. However, medical treatment of erectile dysfunction is not covered by public health insurance creating a small financial barrier for drug treatment. Nowadays prices have become relatively low; for example, four tablets sildenafil cost $12-15 €$. Therefore, the economic component should be much more relevant in the US.

There are several limitations to our study. Although we have been able to build on a health care services research project, recruitment is likely to have included some nonresponder bias. Patients who participated in this survey are likely to have a higher level of health awareness than nonresponders. Moreover, we did not assess the current relationship status and further socioeconomic parameters like the education level. A multivariate analysis within the subset of incontinent patients was not possible because of the small total number. The long follow-up time of 6 years possibly influenced personal attitudes towards impaired functional outcome after RP. On the other hand, this longer interval enabled a validated coverage of patients concerns. This is the first study investigating the utilisation of care for postprostatectomy incontinence and ED in combination with influences on mental health and quality of life in a large and moderately selected cohort from routine care facilities in Germany. Our study population underwent RP in 114 different institutions representing one-fourth of all German providers of RP. Therefore, the bias of individual practice patterns possibly influencing the treatment of incontinence and ED is very low.

\section{Conclusion}

Half of UI patients never utilising treatment for post-prostatectomy UI reported moderate to large problems because of their impairment with a significant decrease in mental health and quality of life. One-third of impotent patients interested in sex but never trying ED treatment reported moderate to large problems because of their ED with a significant decrease in mental health and quality of life. This indicates insufficient utilisation of care in German cancer survivors. Next, we need to explore the reasons for this insufficient utilisation of care. With this improved understanding, we hopefully will develop interventions to raise the level of care for post-prostatectomy urinary incontinence and ED.

Author contributions $\mathrm{MB}$ and $\mathrm{JH}$ had full access to all the data in the study and take responsibility for the integrity of the data and the accuracy of the data analysis. Protocol/project development: MB, JH. Data collection or management: MLS, W, JH. Data analysis: MB, MLS, RK, JH. Manuscript writing/editing: MLS, CT, CG, AB, RK, FH, FKHC, LW, JH. Other: none.

Funding Open Access funding enabled and organized by Projekt DEAL. This work was supported by a research grant from Intuitive 
Surgical Inc. (2017-2019). However, this grant had no influence on the conduct of the study.

\section{Compliance with ethical standards}

Conflict of interest Dr. Huber reports personal fees from Amgen and Janssen, and grants and nonfinancial support from Takeda, outside the submitted work. All other authors declare that they have no conflicts of interest.

Ethical approval Ethical Committee approval was obtained for the HAROW study and for the long-term follow-up.

Informed consent All patients provided written informed consent.

Open Access This article is licensed under a Creative Commons Attribution 4.0 International License, which permits use, sharing, adaptation, distribution and reproduction in any medium or format, as long as you give appropriate credit to the original author(s) and the source, provide a link to the Creative Commons licence, and indicate if changes were made. The images or other third party material in this article are included in the article's Creative Commons licence, unless indicated otherwise in a credit line to the material. If material is not included in the article's Creative Commons licence and your intended use is not permitted by statutory regulation or exceeds the permitted use, you will need to obtain permission directly from the copyright holder. To view a copy of this licence, visit http://creativecommons.org/licenses/by/4.0/.

\section{References}

1. Ficarra V, Novara G, Rosen RC, Artibani W, Carroll PR, Costello A et al (2012) Systematic review and meta-analysis of studies reporting urinary continence recovery after robot-assisted radical prostatectomy. Eur Urol 62(3):405-417

2. Ficarra V, Novara G, Ahlering TE, Costello A, Eastham JA, Graefen $M$ et al (2012) Systematic review and meta-analysis of studies reporting potency rates after robot-assisted radical prostatectomy. Eur Urol 62(3):418-430

3. Steineck G, Helgesen F, Adolfsson J, Dickman PW, Johansson JE, Norlen BJ et al (2002) Quality of life after radical prostatectomy or watchful waiting. N Engl J Med 347(11):790-796

4. Lucas MG, Bosch RJ, Burkhard FC, Cruz F, Madden TB, Nambiar AK et al (2012) EAU guidelines on assessment and nonsurgical management of urinary incontinence. Eur Urol 62(6):1130-1142

5. Wilson LC, Gilling PJ (2011) Post-prostatectomy urinary incontinence: a review of surgical treatment options. BJU Int 107(Suppl 3):7-10

6. Gonzalez R, Merino FG, Vaughn M (1995) Long-term results of the artificial urinary sphincter in male patients with neurogenic bladder. J Urol 154(2 Pt 2):769-770

7. Emanu JC, Avildsen IK, Nelson CJ (2016) Erectile dysfunction after radical prostatectomy: prevalence, medical treatments, and psychosocial interventions. Curr Opin Support Palliat Care 10(1):102-107

8. Menard J, Tremeaux JC, Faix A, Pierrevelcin J, Staerman F (2011) Erectile function and sexual satisfaction before and after penile prosthesis implantation in radical prostatectomy patients: a comparison with patients with vasculogenic erectile dysfunction. J Sex Med 8(12):3479-3486

9. Weissbach L, Stuerzebecher S, Mumperow E, Klotz T, Schnell D (2016) HAROW: the first comprehensive prospective observational study comparing treatment options in localized prostate cancer. World J Urol 34(5):641-647

10. Wei JT, Dunn RL, Litwin MS, Sandler HM, Sanda MG (2000) Development and validation of the expanded prostate cancer index composite (EPIC) for comprehensive assessment of health-related quality of life in men with prostate cancer. Urology 56(6):899-905

11. Martin NE, Massey L, Stowell C, Bangma C, Briganti A, BillAxelson A et al (2015) Defining a standard set of patient-centered outcomes for men with localized prostate cancer. Eur Urol 67(3):460-467

12. van Andel G, Bottomley A, Fossa SD, Efficace F, Coens C, Guerif S et al (2008) An international field study of the EORTC QLQ-PR25: a questionnaire for assessing the health-related quality of life of patients with prostate cancer. Eur J Cancer 44(16):2418-2424

13. Miller DC, Wei JT, Dunn RL, Montie JE, Pimentel H, Sandler HM et al (2006) Use of medications or devices for erectile dysfunction among long-term prostate cancer treatment survivors: potential influence of sexual motivation and/or indifference. Urology 68(1):166-171

14. Aaronson NK, Ahmedzai S, Bergman B, Bullinger M, Cull A, Duez NJ et al (1993) The European Organization for Research and Treatment of Cancer QLQ-C30: a quality-of-life instrument for use in international clinical trials in oncology. J Natl Cancer Inst 85(5):365-376

15. Kroenke K, Spitzer RL, Williams JB, Lowe B (2009) An ultrabrief screening scale for anxiety and depression: the PHQ-4. Psychosomatics 50(6):613-621

16. Baunacke M, Schmidt ML, Thomas C, Groeben C, Borkowetz A, Koch R et al (2020) Long-term functional outcomes after robotic vs. retropubic radical prostatectomy in routine care: a 6-year follow-up of a large German health services research study. World J Urol. 38(7):1701-1709

17. Kim PH, Pinheiro LC, Atoria CL, Eastham JA, Sandhu JS, Elkin EB (2013) Trends in the use of incontinence procedures after radical prostatectomy: a population based analysis. J Urol 189(2):602-608

18. Baunacke M, Schmidt ML, Groeben C, Borkowetz A, Thomas C, Koch $\mathrm{R}$ et al (2020) Decision regret after radical prostatectomy does not depend on surgical approach: 6 year followup of a large German cohort undergoing routine care. J Urol 203(3):554-561

19. Johansson E, Steineck G, Holmberg L, Johansson JE, Nyberg T, Ruutu M et al (2011) Long-term quality-of-life outcomes after radical prostatectomy or watchful waiting: the Scandinavian Prostate Cancer Group-4 randomised trial. Lancet Oncol 12(9):891-899

20. Borges RC, Tobias-Machado M, Gabriotti EN, Dos Santos Figueiredo FW, Bezerra CA, Glina S (2019) Post-radical prostatectomy urinary incontinence: is there any discrepancy between medical reports and patient's perceptions? BMC Urol 19(1):32

21. Litwin MS, Lubeck DP, Henning JM, Carroll PR (1998) Differences in urologist and patient assessments of health related quality of life in men with prostate cancer: results of the CaPSURE database. J Urol 159(6):1988-1992

22. Herkommer K, Niespodziany S, Zorn C, Gschwend JE, Volkmer BG (2006) Management of erectile dysfunction after radical prostatectomy Urologist's assessment vs patient survey responses. Urologe A 45(3):336 (8-42)

23. Philippou YA, Jung JH, Steggall MJ, O'Driscoll ST, Bakker CJ, Bodie JA et al (2018) Penile rehabilitation for postprostatectomy erectile dysfunction. Cochrane Database Syst Rev. 10(10):CD012414

24. Tal R, Jacks LM, Elkin E, Mulhall JP (2011) Penile implant utilization following treatment for prostate cancer: analysis of the SEER-medicare database. J Sex Med 8(6):1797-1804 
25. Shabsigh R, Perelman MA, Laumann EO, Lockhart DC (2004) Drivers and barriers to seeking treatment for erectile dysfunction: a comparison of six countries. BJU Int 94(7):1055-1065

26. Huber J, Streuli JC, Lozankovski N, Stredele RJ, Moll P, Hohenfellner M et al (2016) The complex interplay of physician, patient, and spouse in preoperative counseling for radical prostatectomy: a comparative mixed-method analysis of 30 videotaped consultations. Psychooncology 25(8):949-956

27. Rosing D, Berberich HJ (2004) Disease- and treatment related sexual disorders after radical prostatectomy. A biopsychosocial consideration. Urologe A. 43(3):291-295
28. Baunacke M, Groeben C, Borgmann H, Salem J, Kliesch S, Huber J (2018) Andrology on the Internet: Most wanted, controversial and often primary source of information for patients. Andrologia. 50(2):e12877

Publisher's Note Springer Nature remains neutral with regard to jurisdictional claims in published maps and institutional affiliations. 